\title{
Pressure dependent mechanistic branching in the formation pathways of secondary organic aerosol from cyclic-alkene gas-phase ozonolysis $\dagger$
}

\author{
Jan Lennard Wolf, Stefanie Richters, Josua Pecher and Thomas Zeuch* \\ Received 11th November 2010, Accepted 18th February 2011 \\ DOI: $10.1039 / \mathrm{c0cp02499f}$
}

The gas-phase ozonolysis of cyclic-alkenes (1-methyl-cyclohexene, methylene-cyclohexane, $\alpha$-pinene, $\beta$-pinene) is studied with respect to the pressure dependent formation of secondary organic aerosol (SOA). We find that SOA formation is substantially suppressed at lower pressures for all alkenes under study. The suppression coincides with the formation of ketene ( $\alpha$-pinene, 1-methyl-cyclohexene), ethene (1-methyl-cyclohexene) and the increased formation of $\mathrm{CO}$ (all alkenes) at lower reaction pressures. The formation of these products is independent of the presence of an $\mathrm{OH}$ scavenger and explained by an increased chemical activation of intermediate species in the hydroperoxide channel after the $\mathrm{OH}$ elimination. These findings underline the central role of the hydroperoxide pathway for SOA formation and give insight into the gas-phase ozonolysis mechanism after the stage of the Criegee intermediate chemistry.

\section{Introduction}

Atmospheric particles influence visibility, climate, and human health. ${ }^{1}$ For many clean and polluted environments, the organic fraction of these particles contributes 20 to $70 \%$ of the total nonrefractory mass. ${ }^{2}$ A significant part of the organic fraction is attributed to the formation of secondary organic aerosols (SOA) coming from the gas-phase reactions of alkenes with a variety of different oxidants. Although the contribution of alkene oxidation processes to SOA formation is known for decades, ${ }^{3}$ a detailed knowledge about the mechanism is still missing. This is reflected by the failure of "bottom-up" approaches in predicting atmospheric SOA yields based on extrapolations of data from laboratory experiments. ${ }^{4}$

To anticipate some items for the discussion a more extensive introduction is considered to be appropriate. With respect to unsaturated hydrocarbons, besides the $\mathrm{OH}$ and $\mathrm{NO}_{3}$ initiated oxidation, ${ }^{5,6}$ the ozonolysis reaction in particular is well known to lead to particle formation. Especially for $\alpha$ - and $\beta$-pinene, two of the most abundant terpenes, effects on SOA and SOA component formation have been studied with respect to the dependence of reaction conditions ${ }^{6-11}$ such as $\mathrm{OH}$ initiated or influenced oxidation, ${ }^{6,7}$ humidity, ${ }^{6,8}$ temperature, ${ }^{9}$ presence of Criegee scavengers, ${ }^{8}$ and seed aerosol. ${ }^{10,11}$

These studies brought to light some details of the gas phase oxidation pathways leading to SOA formation being discussed

Georg-August-Universität Göttingen, Institut für Physikalische

Chemie, Tammannstr. 6, 37077 Göttingen, Germany.

E-mail:tzeuch1@gwdg.de

$\dagger$ This article was submitted as part of a collection following the

21 st International Symposium on Gas Kinetics, held in Leuven in July 2010 . in recent experimental and theoretical studies (e.g. ref. 12 and 13 and the literature cited therein). However, to our knowledge the effect of one of the most basic variations of reaction conditions on SOA yields has not been reported yet: the effect of the reaction pressure. In previous studies the pressure effect was addressed in the context of intermediate species formation like $\mathrm{OH}$ radicals or Criegee intermediates $(\mathrm{CI})$ aiming at the elucidation of mechanistic features. ${ }^{14-17}$ The $\mathrm{CI}$ is formed together with a carbonyl compound by the decomposition of the unstable primary ozonide (POZ) ${ }^{18}$ the initial $\mathrm{O}_{3}$-alkene adduct. Its chemical activation with excess energy by $200-250 \mathrm{~kJ} \mathrm{~mol}^{-1} 19$ influences essentially the consecutive chemistry. Theoretical studies have shown that at atmospheric pressure CIs are stabilised by bath gas collisions to a significant degree (e.g. $21 \%$ for $\mathrm{CH}_{2} \mathrm{OO}$ (ref. 17), $20-30 \%$ for $\left(\mathrm{CH}_{3}\right)_{2} \mathrm{COO}$ (ref. 17), $37 \%$ for $\mathrm{CIs}$ from $\beta$-pinene $\left.+\mathrm{O}_{3}\right) \cdot{ }^{13} \mathrm{At}$ low pressures around $10 \mathrm{mbar}$ the stabilisation of CIs is reduced in some cases to less than $1 \% .^{13}$ The importance of CI reactions in chemical models explaining SOA formation is well known and intensively discussed (see e.g. ref. 6, 8 and 13 and the literature cited therein). This has been experimentally tested by added Criegee scavengers leading to reduced ${ }^{8}$ and increased ${ }^{6}$ SOA yields depending on both the scavenger and the alkene. CI scavengers are usually introduced in relatively high concentrations and tend to introduce more chemical complexity in the system. Varying the pressure and monitoring aerosol yields at otherwise identical reaction conditions will, when sensitive, reveal the influence of collision mediated mechanistic branching on the formation pathways of nucleation inducing species within the oxidation mechanism of the pure compound. Moreover, it may offer the chance to identify important intermediates at a later stage than the CI chemistry. A similar idea was formulated and examined 
theoretically for the ozonolysis of symmetric cyclohexenes in a study by Chuong et al. (ref. 20). In this work the stabilisation of CIs and the formation of low volatility products like secondary ozonides (SOZ) were discussed as a function of the alkene size.

In a recent investigation we could show that SOA formation during the ozonolysis of 1-methyl-cyclohexene (MCHe) and methylene-cyclohexane (MCHa) can be effectively suppressed at high alkene conversions (above $1 \mathrm{ppm}$ ) when kinetic parameters like absolute reaction rates are changed. Thereby critical experimental conditions for SOA formation have been revealed indicating a significant influence of transient species chemistry linked to CIs or peroxy radicals. ${ }^{21}$ These experiments were performed at 1 bar with the initial phase of reaction, when the reactants are mixed, proceeding under low pressure conditions. The variation of mixing conditions proved to be sensitive on aerosol yields. However, we did not directly examine the pressure dependence at this study. We anticipate here that the results of the present study will alter the conclusions of the previous work.

In the present study we report on the pressure effect on SOA yields from the ozonolysis of $\mathrm{MCHe}$ and $\mathrm{MCHa}$ and the structurally similar pinenes ( $\alpha$ and $\beta$ ). To this end a new reaction cell design and measurement procedure has been used. The pressure dependent formation of final gas phase products is studied experimentally and possible links to observed SOA yields are discussed. The experimental procedure reported here provides a straightforward access to alkene $+\mathrm{O}_{3}$ rate coefficients, which is demonstrated for the four alkenes under study.

\section{Experimental}

\section{Reactor}

Here we report a new reaction cell design and measurement procedure being applied to examine pressure effects on aerosol yields (Fig. 1). The set-up consists of a reaction cell with a volume of $64 \mathrm{~L}$. First, the reactant gases are filled in two premixing chambers of $40 \mathrm{~L}$ volume. One chamber is used as an ozone reservoir and equipped with UV optics to measure $\mathrm{O}_{3}$ concentrations. Two systems are used: A UV-lamp (Philips TUV PL-L 36W/4P 1CT) is used as a light source and two photodiodes (Laser Components JEC 1C) measure the reference UV intensity and the intensity, when the beam has passed the premixing chamber (circle in Fig. 1). The photodiode signals are continuously recorded and used for monitoring the ozone concentration in the premixing chamber based on the known ozone absorption coefficient at $253.7 \mathrm{~nm}$. An additional calibration is achieved by measuring ozone concentrations in the reaction cell and the premixing chamber using a commercial ozone analyser (Environnement S. A. O341M, accuracy $1 \mathrm{ppb}$ ). Both the ozone chamber and the reaction cell have Teflon coated walls to minimize adsorption at the wall. Ozone is produced by a commercial ozone generator (Sander 301.7) and stored at low temperature (cold trap, $220 \mathrm{~K}$ ) by adsorption on silica beads in quartz bottles (left block of the ozone generator). The ozone premixing chamber is filled from the reservoir bottles by flushing with He. The reaction cell is equipped with

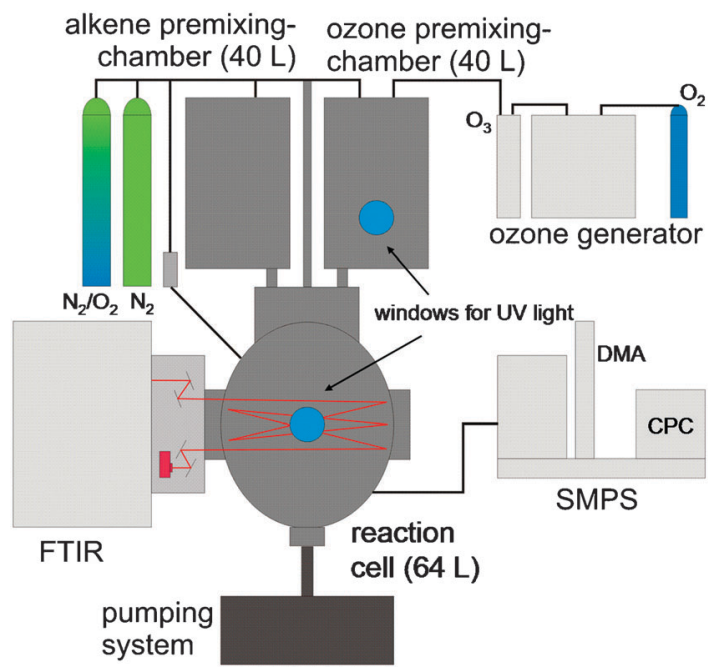

Fig. 1 Scheme of the experimental arrangement allowing a fast reactant mixing. For more details see text.

multi-reflection White-optics (12 $\mathrm{m}$ path length), which are connected with an infra-red spectrometer (Bruker IFS 66) in order to determine reactant concentrations (alkenes, ozone) and the main reaction products and their yields. The concentrations in the alkene premixing chamber are determined volumetrically and they are used for the calibration of reactant specific IR absorption bands (resolution $1 \mathrm{~cm}^{-1}$ ). A particle classifier (TSI SMPS 3936 with NDMA (3085) and LDMA (3081) as well as a 3022 CPC) is connected for particle measurements. We operate the SMPS with 2 litres per minute (lpm) sheath flow and $0.2 \mathrm{lpm}$ sample flow. The total particle number (number yield) is the integrated particle size distribution; the mass yield is derived from the size distribution assuming spherical particles and a density of $1.2 \mathrm{~g} \mathrm{~cm}^{-1}$.

After the reactants the bath gas is filled in the premixing chambers up to pressures between 50 mbar and 1000 mbar (synthetic air, nitrogen and oxygen, depending on the experiment). Then the reaction mixture is prepared by simultaneously opening the valves between the reaction chamber and the premixing chambers. Their volume ratio of $(2.40 \mathrm{~L}=80 \mathrm{~L}) /$ $64 \mathrm{~L}$ leads to pressures between $20-450$ mbar in the reaction cell, when the expansion from the premixing chamber is stopped after $3 \mathrm{~s}$ ( $c a .80 \%$ relaxation). The pressures in the premixing chambers are monitored by pressure gauges (MKS Baratron 10 mbar, 1000 mbar) with accuracies of $10^{-4} \mathrm{mbar}$ and 0.1 mbar. The pressure in the reaction cell is monitored with an accuracy of 0.1 mbar (MKS Baratron 1000 mbar). The fast filling and mixing minimizes the time period of large concentrations gradients. Therefore $90-99 \%$ of the ozone is consumed at a defined pressure even at relatively high reactant concentrations due to the short mixing time. For several experiments at reaction pressures below 20 mbar the filling procedure is changed with respect to the low pressure gradients, which make a controlled simultaneous filling from two premixing chambers more difficult. Here the alkene was filled directly to the reaction chamber and the ozone/oxygen/air mixture was prepared in the ozone premixing chamber. Again a fast filling and mixing was achieved by expanding this mixture to the reaction cell. 
For measuring pressure dependent aerosol yields the reaction cell is filled to 1 bar with synthetic air after more than $95 \%$ of ozone has been consumed at the chosen reaction pressure. The fast reactant consumption allows the time separation of gas phase kinetics at various pressures from aerosol classification being restricted to 1 bar. For achieving this goal it is suitable to apply amounts of alkene, which are higher than in smog chamber studies. However, they are similar to many recent studies on SOA formation in smaller static reactors or in flow tubes. ${ }^{8,22,23}$

In the preparation run of each experiment the reaction cell is passivated by ozone. After exposing the cell for 10 minutes with around $800 \mathrm{ppm}$ ozone particle formation is effectively suppressed when ozone (up to $10 \mathrm{ppm}$ ) is filled in the cell without alkenes. The recorded SMPS data are similar to probing synthetic air without ozone addition. The loss of aerosol to the wall was estimated by measuring and modelling the evolution of size distributions. For this purpose we produced SOA from the reaction of 1 ppm ozone with $10 \mathrm{ppm} \mathrm{MCHa}$ and measured the particle size distribution 3 times at 1 bar in intervals of 20 minutes. The connection to the SMPS was opened and closed for each measurement. Assuming the absence of coagulation and a first-order time law for particle wall loss gives a wall loss rate of $c a .1 \%$ per min. To assess the fraction of particle number loss by coagulation we used different simplified coagulation models adopted to the observed increase of the median of the size distribution. This decreases the resulting wall loss rates to $0.5-0.8 \%$ per min. In addition the loss of particles in the cell was characterised using test particles being produced by a constant output atomizer (TSI 3076) from a sodium chloride solution. This test was less quantitative due to a higher coagulation rate, but agreed qualitatively with SOA particle measurements. More details are found in ref. 24 . We did not find any pressure effects on the wall loss of aerosols. This was checked by producing SOA at 50 mbar from $\mathrm{MCHa}+\mathrm{O}_{3}(0.1 \mathrm{~Pa}$ ozone, $1 \mathrm{~Pa} \mathrm{MCHa})$ with residence times of 5 minutes and 20 minutes at 50 mbar. The slightly lower aerosol yield observed with 20 min residence time is in agreement with the wall loss observed at 1 bar.

\section{Chemicals}

Commercially available chemicals were used without further purification: synthetic air $\left(79.5 \% \quad \mathrm{~N}_{2} / 20.5 \% \quad \mathrm{O}_{2}, \geq 99.9990 \%\right)$, nitrogen $(\geq 99.9990 \%)$, oxygen $(\geq 99.995 \%)$, helium ( $\geq 99.996 \%$ ), all Air Liquide; sulfur hexafluoride ( $\geq 99.9 \%$ ), Linde; 1-methyl-1-cyclohexene ( $\geq 95 \%$ ), methylene-cyclohexane ( $\geq 99 \%$ ), all Fluka; $\alpha$-pinene ( $\geq 99 \%$ ), $\beta$-pinene $(\geq 99 \%)$, all Aldrich.

\section{Results and discussion}

\section{Kinetics}

The design of the experimental arrangement allows the fast preparation of a homogeneous reaction mixture in terms of initial reactant concentrations and pressure. When the initial alkene and ozone concentrations are chosen such that around $80 \%$ of ozone is reacted within the first 5-10 minutes the alkene and ozone consumption can be monitored by IR spectroscopy.
Averaging IR spectra in intervals of $32 \mathrm{~s}$ the ozone and alkene concentration-time profiles are a sensitive measure for the alkene $+\mathrm{O}_{3}$ rate coefficient $\left(k=k\right.$ (alkene $\left.+\mathrm{O}_{3}\right)$ when no other specification is given). For the alkene ozone reaction the consumption of the alkene by secondary reactions, predominantly by the reaction with $\mathrm{OH}$ radicals, has to be taken into account. This can be achieved either by using $\mathrm{OH}$ radical scavengers ${ }^{25,26}$ or by correcting the alkene consumption for secondary reactions. ${ }^{27}$ To this end the amount of reacted alkene per reacted ozone molecule is determined, which implies an absolute value of the stoichiometric factor $\nu_{\text {alkene }}$ larger than one in the mass balance of the rate law: With $Y_{\mathrm{OH}}$ being the $\mathrm{OH}$ yield in the alkene $+\mathrm{O}_{3}$ reaction and under the assumption that only $\mathrm{OH}$ radicals contribute to additional alkene consumption we find

$$
-\nu_{\text {alkene }}=1+Y_{\mathrm{OH}}=\frac{\Delta[\text { alkene }]}{\Delta\left[\mathrm{O}_{3}\right]}
$$

As the reaction alkene $+\mathrm{O}_{3}$ is bimolecular, the right hand side of the rate law still reads

$$
\frac{1}{\nu \text { alkene }} \frac{\mathrm{d}[\text { alkene }]}{\mathrm{d} t}=k\left[\mathrm{O}_{3}\right][\text { alkene }]
$$

After integration we have

$$
\frac{1}{\nu_{\text {alkene }}\left[\mathrm{O}_{3}\right]_{0}+[\text { alkene }]_{0}} \ln \left(\frac{\left[\mathrm{O}_{3}\right]_{0}[\text { alkene }]}{[\text { alkene }]_{0}\left[\mathrm{O}_{3}\right]}\right)=k t
$$

This integrated time law is used to analyse the experimental ozone/alkene time profiles. $k$ is derived from a linear fit to the experimental profiles and averaged for several starting concentrations.

In Fig. 2 the analysis of the concentration time profiles is illustrated for the reaction $\mathrm{MCHa}+\mathrm{O}_{3}$. The upper panel shows the evolution of the partial pressures of $\mathrm{MCHa}$ and $\mathrm{O}_{3}$ with time for one experiment. The lower panel shows $k t v s$. $t$ plots for a series of experiments. Three of these experiments were performed in the presence of the $\mathrm{OH}$ scavenger cyclohexane. In order to avoid larger errors in the integration of $\mathrm{O}_{3}$ and alkene IR bands due to an overlap with cyclohexane bands we limited the addition of cyclohexane to $25 \pm 1 \mathrm{~Pa}$. As a consequence alkene consumption by $\mathrm{OH}$ was only suppressed up to about $75 \%$. Thus the absolute value of $\nu_{\text {alkene was still }}$ larger than 1 and accordingly used in the kinetic analysis based on eqn (1)-(3). However, this variation of experimental conditions as well as the variation of initial alkene and $\mathrm{O}_{3}$ concentrations showed no obvious impact on the $k$ values being determined along the procedure explained above. Therefore $k$ is the average of the set of derived $k$ values and the statistical error $(95 \%$ confidence interval) is given as a lower estimate of the error margins. In Table 1 the results for $\mathrm{MCHa}+\mathrm{O}_{3}$ are shown together with those for $\mathrm{MCHe}$, $\alpha$-pinene, $\beta$-pinene $+\mathrm{O}_{3}$ and compared to literature data. More details are given in ref. 24. We have found that for all alkenes under study the rate coefficients reported here are in good agreement with previous work. These results suggest that the fast reactant mixing experiments allow a straightforward determination of alkene $+\mathrm{O}_{3}$ rate coefficients. Only for $\mathrm{MCHa}+\mathrm{O}_{3}$ we see a larger deviation from one of the literature values, which was determined relatively to $1-\mathrm{C}_{4} \mathrm{H}_{8}+\mathrm{O}_{3} \cdot{ }^{30}$ 


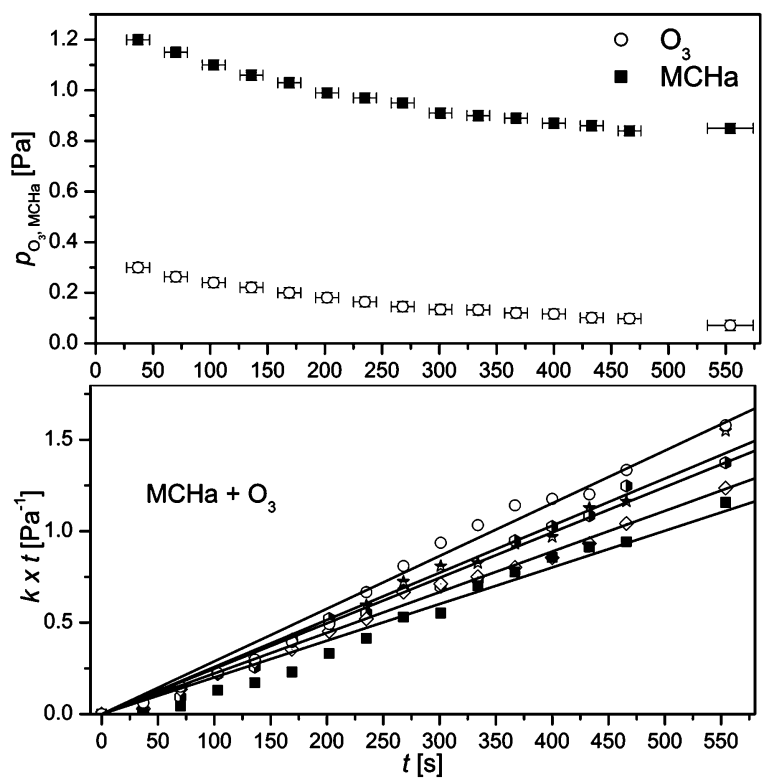

Fig. 2 Upper panel: Partial pressure of the reactants $\mathrm{O}_{3}$ and $\mathrm{MCHa}$ as a function of reaction time. Lower panel: $k t v s$. $t$ plots for various initial conditions with $k t$ derived according to eqn (3): (all partial pressures are given in $\mathrm{Pa}) . \mathrm{O}: p_{0}\left(\mathrm{O}_{3}\right)=0.309, p_{0}(\mathrm{MCHa})=1.32, p($ cyclohexane $)=$ $25.9, p=50$ mbar; $: p_{0}\left(\mathrm{O}_{3}\right)=0.31, p_{0}(\mathrm{MCHa})=1.21, p=1000 \mathrm{mbar}$ $\star: p_{0}\left(\mathrm{O}_{3}\right)=0.272, p_{0}(\mathrm{MCHa})=1.32, p=500$ mbar; $\odot: p_{0}\left(\mathrm{O}_{3}\right)=$ $0.272, p_{0}(\mathrm{MCHa})=1.33, p($ cyclohexane $)=24.3 ; \mathbf{\square}: p_{0}\left(\mathrm{O}_{3}\right)=0.535$, $p_{0}(\mathrm{MCHa})=0.484, p($ cyclohexane $)=24.5, p=500$ mbar.

Table 1 Alkene $+\mathrm{O}_{3}$ reaction: Results on rate coefficients in the present study ( $T=298 \pm 1 \mathrm{~K}$ for all experiments) and in previous work

\begin{tabular}{lll}
\hline Alkene & $k / \mathrm{cm}^{3} \mathrm{~s}^{-1}$ at $298 \mathrm{~K}$ & Refs. \\
\hline $\mathrm{MCHa}^{a, b}$ & $(1.0 \pm 0.2) \times 10^{-17}$ & This work \\
& $(1.06 \pm 0.19) \times 10^{-17}$ & 28 \\
& $1.2 \times 10^{-17}$ & 29 \\
$\mathrm{MCHe}^{c}$ & $(2.82 \pm 0.36) \times 10^{-17}$ & 30 \\
& $(1.81 \pm 0.13) \times 10^{-16}$ & This work \\
& $1.7 \times 10^{-16}$ & 29 \\
$\alpha_{-P i n e n e}{ }^{d}$ & $(1.46 \pm 0.10) \times 10^{-16}$ & 25 \\
& $(1.66 \pm 0.12) \times 10^{-16}$ & 31 \\
& $(8.5 \pm 0.5) \times 10^{-17}$ & This work \\
& $\left(8.7 \times 10^{-17}\right.$ & 32 \\
$\beta$-Pinene & & 33 \\
& $(11 \pm 0.2) \times 10^{-17}$ & 26 \\
& $(9.0 \pm 0.6) \times 10^{-17}$ & 34 \\
& $(1.6 \pm 0.2) \times 10^{-17}$ & This work \\
& $(1.48 \pm 0.16) \times 10^{-17}$ & 32 \\
& $(2.35 \pm 0.27) \times 10^{-17}$ & 30 \\
& & 33
\end{tabular}

${ }^{a} p_{0}\left(\mathrm{O}_{3}\right): 0.18-0.62 \mathrm{~Pa} ; p_{0}(\mathrm{MCHa}): 0.30-1.36 \mathrm{~Pa} ; p$ : 50-1000 mbar. ${ }^{b}$ Some experiments were performed in the presence of cyclohexane. ${ }^{c} p_{0}\left(\mathrm{O}_{3}\right): 0.16-0.47 \mathrm{~Pa} ; p_{0}(\mathrm{MCHe}): 0.24-0.47 \mathrm{~Pa} ; p: 500$ mbar. ${ }^{d} p_{0}\left(\mathrm{O}_{3}\right)$ : 0.28-0.41 Pa; $p_{0}\left(\alpha\right.$-pinene): $0.50-0.82 \mathrm{~Pa} ; p$ : 500 mbar. ${ }^{e} p_{0}\left(\mathrm{O}_{3}\right)$ : 0.34-1.83 Pa; $p_{0}(\beta$-pinene): 0.74-2.07 Pa; $p$ : 500 mbar.

We note here that the effect of $\mathrm{HO}_{2}$ reactions has been neglected in the kinetic analysis. $\mathrm{HO}_{2}$ may react with $\mathrm{O}_{3}$ leading to additional $\mathrm{O}_{3}$ loss. Then eqn (1) would no longer hold. However, this is probably a minor effect. The reason is the relatively fast $\mathrm{O}_{3}$ consumption under the significant alkene excess concentrations, which have been used in most of our experiments. A recent study by Malkin et al. ${ }^{35}$ on $\mathrm{OH}$ and $\mathrm{HO}_{2}$ yields for the ozonolysis of isoprene provides absolute $\mathrm{HO}_{2}$ concentrations for a typical experiment. A maximum $\mathrm{HO}_{2}$ concentration of $3.5 \times 10^{10}$ molecules $\mathrm{cm}^{-3}$ was determined for the reaction of $1 \mathrm{ppm}$ isoprene with $8 \mathrm{ppm}$ ozone. This information allows to roughly estimate the $\mathrm{HO}_{2}$ concentration in our experiments. Assuming similar $\mathrm{HO}_{2}$ yields of $20-40 \%$ leads to $\mathrm{HO}_{2}$ concentrations of about (1-2) $\times 10^{11}$ molecules $\mathrm{cm}^{-3}$ for a typical experiment with MCHa. This estimation is based on the similar rate coefficients for $\mathrm{MCHa} /$ isoprene $+\mathrm{O}_{3}$ (ref. 33) and the related assumption that the faster initial reaction rate (factor 3-4) in our experiments increases absolute $\mathrm{HO}_{2}$ concentrations by the same factor. Now we can compare $\mathrm{O}_{3}$ loss by the reactions with $\mathrm{MCHa}$ and $\mathrm{HO}_{2}$ at the $\mathrm{HO}_{2}$ concentration peak. The reaction $\mathrm{O}_{3}+\mathrm{HO}_{2}\left(k=2.0 \times 10^{-15} \mathrm{~cm}^{3} \mathrm{~s}^{-1}\right.$; ref. 36) is a factor of 200 faster than $\mathrm{MCHa}+\mathrm{O}_{3}$. But the typical alkene concentration of $3 \times 10^{14}$ molecules $\mathrm{cm}^{-3}$ ( $c$ a $13 \mathrm{ppm}$ ) is a factor of 3000 above the $\mathrm{HO}_{2}$ concentration. This indicates that for the slowest alkene $+\mathrm{O}_{3}$ reaction additional $\mathrm{O}_{3}$ loss due to $\mathrm{HO}_{2}$ chemistry is probably limited to $10-15 \%$ and will not significantly change the results. For the other alkenes the effect may be less pronounced since $\mathrm{HO}_{2}+\mathrm{O}_{3}$ is less competitive. However, $\mathrm{HO}_{2}$ reactions might contribute to the curvature seen in the regression fits of Fig. 2. Higher $\mathrm{HO}_{2}$ yields being reported for smaller alkenes ${ }^{37}$ would increase the $\mathrm{HO}_{2}$ impact on the kinetic analysis. Clearly, a more detailed discussion of the reaction kinetics is of interest but beyond the scope of the present study and will be presented elsewhere. We note that the short mixing time allows the use of comparable high reactant concentrations (see captions of Table 1) enhancing the time scale of kinetics compared to the time scale of unwanted, diffusion controlled wall loss processes. This point is of importance for the discussion of pressure dependent SOA yields in the following section.

\section{Pressure dependent SOA yields}

This section is organised as follows. First, the experimental results on pressure dependent SOA yields will be shown. Then further experiments will be presented and discussed focussing on the kinetic nature of the findings. Finally, the results are discussed in comparison to recent studies in the literature.

The pressure dependent yields of SOA have been determined in terms of particle number and aerosol mass for MCHa and $\mathrm{MCHe}$ by reacting $(0.1 \pm 0.01) \mathrm{Pa} \mathrm{O}_{3}(1 \mathrm{ppm}$ for $1 \mathrm{bar})$ and for $\alpha$-pinene and $\beta$-pinene by reacting $(0.05 \pm 0.01) \mathrm{Pa} \mathrm{O}_{3}$ (500 ppb for 1 bar) with the alkenes being in excess in all experiments. The initial alkene concentrations were chosen such that more than $95 \%$ of the ozone is consumed within 5 minutes. This can be deduced from the known rate coefficients being confirmed in the present study (see the previous section). It is achieved that more than $90 \%$ of the ozone is consumed at a defined pressure under homogenous conditions since the ozone consumption during the $3 \mathrm{~s}$ mixing time does not exceed $5 \%$. After the reaction period, which was 5 or 10 minutes for most of the experiments, the reaction cell was filled to 1 bar with synthetic air. Then the SMPS system was activated and five particle size distributions were recorded. When a stable size distribution was achieved three size distributions were 
integrated and averaged, yielding the total particle number and the total particle mass. Usually the scan numbers $2-4$ were used since during the first scan the sampling flows to the SMPS did not show the desired constancy.

In Fig. 3 aerosol yields as a function of reaction pressure are plotted for all alkenes under study. Representative error bars are given for the data point at the highest pressure. They show the statistic error ( $95 \%$ confidence level) for 10 consecutive experiments with similar initial conditions. An error estimate is given for one low pressure data point, which is confirmed by 3-4 experiments at similar conditions. These measurements indicate that an overall accuracy of $\pm 25 \%$ is a realistic estimate for this kind of experiment. In all cases the aerosol yields in terms of number and mass are significantly reduced with decreasing reaction pressure, especially below $100 \mathrm{mbar}$. This is illustrated in Fig. 4, which displays the evolution of the size distribution for $\mathrm{MCHa}+\mathrm{O}_{3}$ with decreasing pressure and the shift to larger particle size medians at lower pressures.

Some differences are found when comparing the pressure dependency of SOA yields for the 4 alkenes. First, the pinenes show a clear difference for both number and mass yield between high ( $p>\sim 50 \mathrm{mbar}$ ) and low pressure ( $p<\sim 50 \mathrm{mbar}$ ) conditions: In the high pressure regime aerosol yields are less
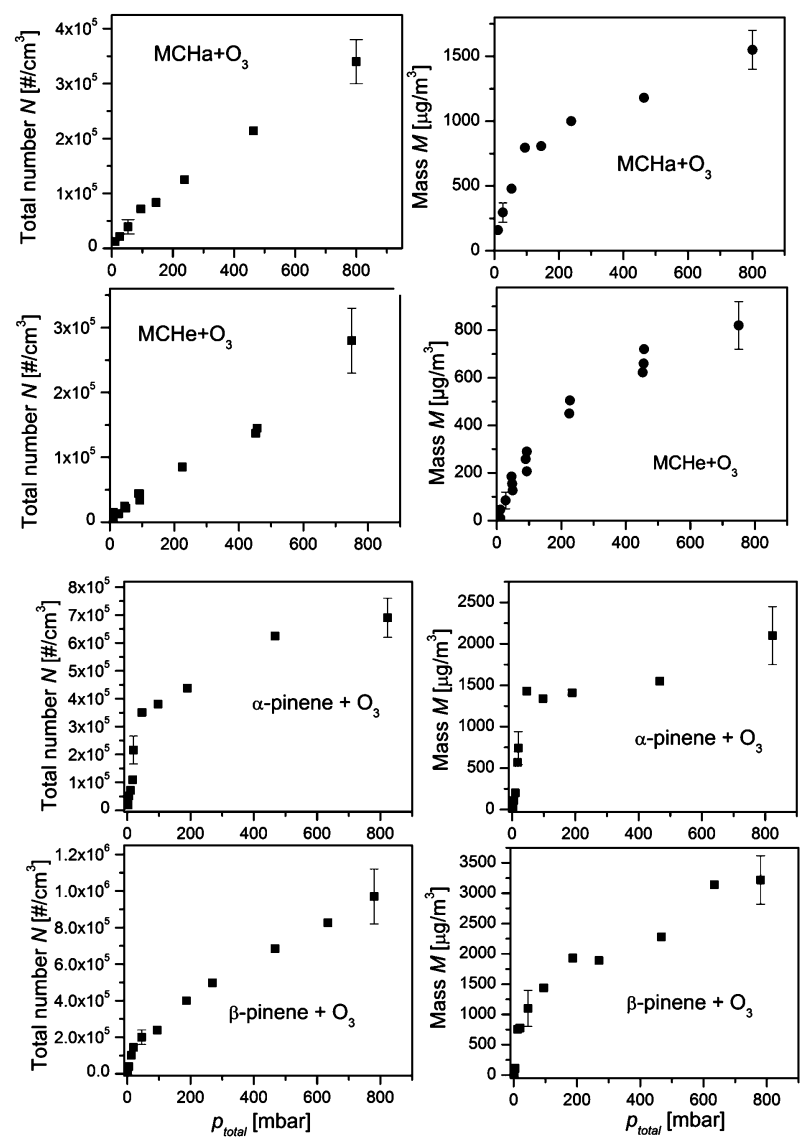

Fig. 3 Aerosol yields in total number and mass are shown as a function of reaction pressure for the reactions of $0.1 \mathrm{~Pa}(1 \mathrm{ppm}$ at $1 \mathrm{bar})$ ozone with $3 \mathrm{~Pa}$ (30 ppm at 1 bar) $\mathrm{MCHa}$ and $0.2 \mathrm{~Pa}$ (2 ppm at 1 bar) $\mathrm{MCHe}$ (upper panels) and for the reaction $0.05 \mathrm{~Pa}(500 \mathrm{ppb}$ at $1 \mathrm{bar}$ ) ozone with $1 \mathrm{~Pa}(10 \mathrm{ppm}$ at 1 bar) $\alpha$-pinene and $3 \mathrm{~Pa}(30 \mathrm{ppm}$ at 1 bar) $\beta$-pinene (lower panels).

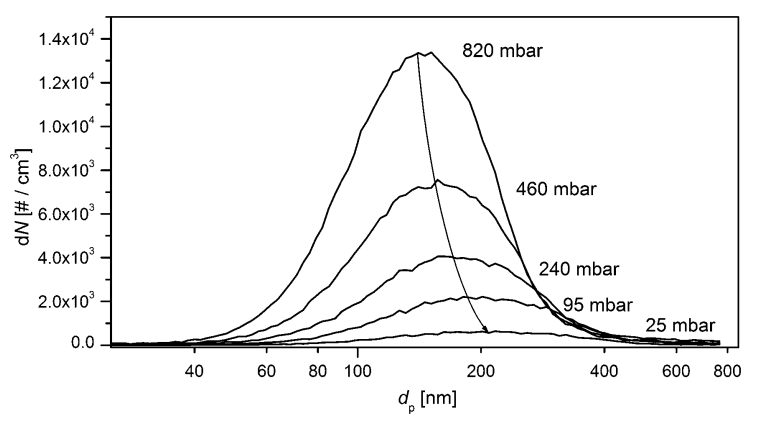

Fig. 4 Evolution of the particle size distribution with reaction pressure for the reaction of $3 \mathrm{~Pa}(30 \mathrm{ppm}$ at $1 \mathrm{bar}) \mathrm{MCHa}$ with $0.1 \mathrm{~Pa}\left(1 \mathrm{ppm}\right.$ at 1 bar) $\mathrm{O}_{3}$ between $820-25$ mbar. The curved arrow indicates the median of the size distribution.

affected by a change in bath gas pressure, while in the low pressure regime a high sensitivity is found on particle number and mass yield with aerosol formation being largely suppressed below 10 mbar. We note that for $\alpha$-pinene the SOA mass yield is nearly constant above 50 mbar. The separation of high and low pressure conditions is much less pronounced for the $\mathrm{C} 7$ alkenes. Here only the mass yields, especially for $\mathrm{MCHa}+\mathrm{O}_{3}$, clearly show a steeper slope at pressures below 100 mbar, whereas the number yields only show a minor increase of the gradients at lower pressures for both $\mathrm{C} 7$ alkenes. These observations are further depicted in Fig. 5 where aerosol yields are shown being normalised against the maximum around 500 mbar. By tentatively assigning low pressure slopes the difference between pinenes and $\mathrm{C} 7$ alkenes is indicated in the upper panel. In the lower panel the larger slope of mass yields for $\mathrm{MCHa}+\mathrm{O}_{3}$ can be seen.
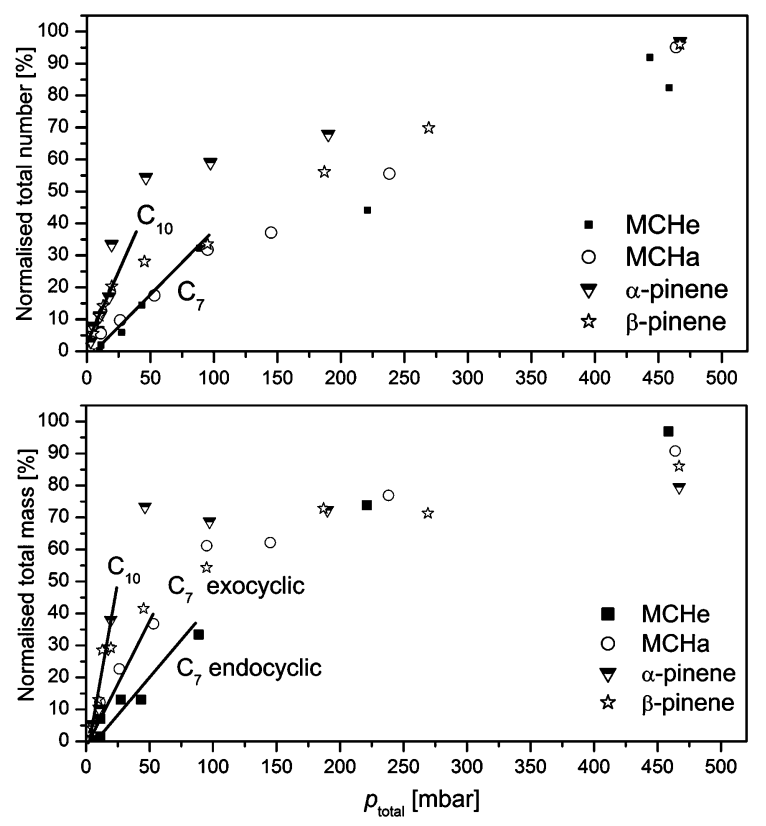

Fig. 5 Normalised aerosol yields in number and mass are shown as a function of reaction pressure for the reactions of $0.1 \mathrm{~Pa}(1 \mathrm{ppm}$ at $1 \mathrm{bar})$ ozone with $3 \mathrm{~Pa}$ (30 ppm at 1 bar) $\mathrm{MCHa}$ (circles) and $0.2 \mathrm{~Pa}$ (2 ppm at 1 bar) $\mathrm{MCHe}$ (squares) as well as $0.05 \mathrm{~Pa}$ (500 ppb at 1 bar) ozone with $1 \mathrm{~Pa}(10 \mathrm{ppm}$ at $1 \mathrm{bar}) \alpha$-pinene (triangles) and $3 \mathrm{~Pa}(30 \mathrm{ppm}$ at $1 \mathrm{bar}$ ) $\beta$-pinene (stars). 
In general we see that for the lowest reaction pressures (5-10 mbar) SOA formation is almost completely suppressed for all alkenes, also in terms of mass yields. This is an important finding, because the pressure shows a strong influence on aerosol mass build up, which is usually studied at low alkene conversion in smog chamber experiments (see e.g. ref. 9 and 11). For such laboratory experiments the aerosol mass growth can be modelled as a function of the amount of hydrocarbon being reacted. ${ }^{38}$ The present study shows that the reaction pressure is an important parameter in this context besides the stoichiometric yield of condensable species, gas-particle partitioning coefficients, and concentrations of preexisting aerosol being discussed by Kroll and Seinfeld. ${ }^{38}$ For the conditions of our experiments (high aerosol mass yields) the aerosol mass growth shows a linear dependence on the amount of alkene being reacted when the pressure is kept constant. This was tested and confirmed in experiments using different initial $\mathrm{O}_{3}$ concentrations. In general the identification of critical parameters for aerosol mass build up may help to elucidate the chemical aspects of phase partitioning. At the conditions where aerosol mass build up starts $(\sim 5-10 \mathrm{ppb}$ pinene conversion) interesting SOA features appear like higher $\mathrm{O}: \mathrm{C}$ ratios or particle densities indicating that unidentified products with a very low volatility compose a significant fraction of the particle-phase mass. ${ }^{11}$ Complementary information is expected on the chemistry of products of low volatility when pressure dependent gas phase product yields are analysed. Species with higher yields at lower pressures are produced by unimolecular decomposition reactions competing with pathways to SOA formation. This issue will be discussed in the next section.

The reduced pressure implicates several changes in the reaction system which must be taken into account before further conclusions can be drawn. The most basic and least critical effect is the reduction of $\mathrm{O}_{2}$ partial pressure which is inevitable at reaction pressures below 200 mbar. To assess the influence of the $\mathrm{O}_{2}$ partial pressure we determined SOA yields at 500 mbar reaction pressure with the $\mathrm{O}_{2}$ partial pressure being lowered from 100 mbar to 1 mbar. Our finding was that SOA yields were unaffected within the experimental uncertainty for all alkenes. Seemingly, the reduction of the time scale for the pseudo first-order kinetics of $\mathrm{O}_{2}$ addition to intermediate alkyl radicals is not critical. Peroxy-radical $\left(\mathrm{RO}_{2}\right)$ formation via $\mathrm{R}+\mathrm{O}_{2}$ is the main influence of $\mathrm{O}_{2}$ on the SOA formation pathways and the initial step for further increasing the $\mathrm{O}: \mathrm{C}$ ratio in the final products. The consecutive $\mathrm{RO}_{2}$ chemistry is of high importance for SOA formation but our understanding is still incomplete (see refs. 39 and 40). The kinetic bottleneck is obviously the much slower $\mathrm{RO}_{2}$ chemistry, making the rate of $\mathrm{RO}_{2}$ formation insensitive for product formation in the consecutive $\mathrm{RO}_{2}$ reactions. To our knowledge the influence of the $\mathrm{R}+\mathrm{O}_{2}$ reaction rate on the consecutive chemistry has not been directly addressed so far in atmosphere related studies on $\mathrm{RO}_{2}$ kinetics. However, such aspects are the key for understanding the low temperature combustion (550-800 K) of larger $n$-alkanes and therefore have been studied in detail for elevated temperatures (see e.g. ref. 41 and references cited therein). It is shown in ref. 41 by reaction sensitivity analysis that the reaction rate of $\mathrm{R}+\mathrm{O}_{2}$ is not sensitive on the spectrum of intermediate and final products at 550-650 K, which is in line with the observation in the present study at atmospheric temperature.

A more critical aspect of the pressure reduction is the faster time scale of diffusion processes within the reaction centre of the reactor. This implies that wall effects may exhibit a stronger influence at lower pressures. It is at least conceivable that SOA precursor species are deactivated by wall collisions being much more likely at lower pressures (see discussion in ref. 9). As discussed above, we applied significant alkene excess concentrations in all experiments enhancing the kinetics such that after $5 \mathrm{~min} 95 \%$ of the ozone is consumed. The fast kinetics favour reactive collisions compensating for the longer mean free path at lower pressures. Since SOA formation is a fast process at such reactant concentrations ${ }^{23}$ wall deactivation is not likely to have a significant influence. Since we cannot directly examine the wall chemistry, a different rigorous experimental test is required. This can be achieved by measuring the SOA yield in different bath gases at identical pressures. When the pressure effect is of kinetic nature, change of the bath gas in the series from $\mathrm{He}$ to $\mathrm{N}_{2} / \mathrm{O}_{2}$ to $\mathrm{SF}_{6}$ will change the collision induced stabilisation of the chemically highly activated intermediates. A measure for the energy removed by collisions is given by the quantity $\Delta E_{\text {down }}{ }^{42}$ For vibrationally excited toluene $\Delta E_{\text {down }}$ values are found in the literature ranging from $70 \mathrm{~cm}^{-1}(\mathrm{He})$, to $130 \mathrm{~cm}^{-1}\left(\mathrm{~N}_{2}\right)$ and $400 \mathrm{~cm}^{-1}$ $\left(\mathrm{SF}_{6}\right)$. Toluene is similar in molecular mass and chemical structure with the intermediates being formed during the ozonolysis of the $\mathrm{C} 7$ alkenes under study. Therefore $\Delta E_{\text {down }}$ values and collision frequencies based on Lennard-Jones parameters of toluene ${ }^{42}$ provide a reasonable estimate for the relative efficiency in collisional stabilisation of the different bath gases.

The aspect of transport processes is linked to the diffusion process. The extent of diffusion controlled processes is in a first approximation proportional to the diffusion coefficients. According to Chapman-Enskog theory ${ }^{43}$ the binary diffusion coefficient $D_{\mathrm{AB}}$ of species $\mathrm{A}$ and $\mathrm{B}$ is anti-proportional to the pressure and the square of the collision diameter $\sigma(\mathrm{AB})=(d(\mathrm{~A})+d(\mathrm{~B}))$ and proportional to the square root of the inverse molar masses $(1 / \mathrm{M}(\mathrm{A})+1 / \mathrm{M}(\mathrm{B}))^{0.5}$. Assuming that the diameter of the particle precursor being deactivated at the wall is not smaller than that for the alkene, the following estimation of the binary diffusion coefficients applies: Comparing $\mathrm{SF}_{6}$ and $\mathrm{N}_{2}$ relative to cyclohexane (as a proxy for the $\mathrm{C} 7$ alkenes) the increase in $\sigma(\mathrm{AB})$ is in the simplest approximation from Lennard-Jones parameters $\sigma\left(\mathrm{SF}_{6}\right.$-cyclohexane $) /$ $\sigma\left(\mathrm{N}_{2}\right.$-cyclohexane $) \approx 5.6 \AA / 5.0 \AA=1.11$, which would lead to $22 \%$ increase in $D_{\mathrm{AB}}$. Comparing $(1 / \mathrm{M}(\mathrm{A})+1 / \mathrm{M}(\mathrm{B}))^{0.5}$ for $\mathrm{N}_{2}$ and $\mathrm{SF}_{6}$ with cyclohexane an increase of around $60 \%$ would appear. Thus the bath gas change from $\mathrm{N}_{2} / \mathrm{O}_{2}$ to $\mathrm{SF}_{6}$ would be equivalent to increasing the pressure by a factor of 1.75 for the diffusion time scale. A similar estimation for $\mathrm{He} /$ cyclohexane gives an decrease in $D_{\mathrm{AB}}$, which is equivalent to a pressure decrease by a factor of 2.93 leading to a significantly higher sensitivity for the bath gas change to He. The effect on collisional stabilisation can be roughly estimated by an increase of about a factor of 3 for $\mathrm{SF}_{6}$ compared to a reduction of a factor of 1.3 for $\mathrm{He}$, when collision efficiencies 
$\beta^{44}$ are estimated from $\Delta E_{\text {down }}$ values and collision frequencies. Hence the effect of the bath gas change on SOA yields should be much more pronounced for $\mathrm{He}$ when being diffusion controlled and for $\mathrm{SF}_{6}$ when being controlled by collisional stabilisation of chemically activated intermediates. This was tested by measuring SOA yields at pressures around $50 \mathrm{mbar}$, where a significant reduction of SOA yields is found for the C7-alkenes. The experiments in $\mathrm{He}$ and $\mathrm{SF}_{6}$ are limited to about 100 mbar, which limits the errors in the SOA classification after filling the reaction cell to 1000 mbar with synthetic air. Since 10 mbar $\mathrm{O}_{2}$ are added in all experiments, experiments below 30 mbar are less significant with respect to the bath gas mixture. In Fig. 6 the SOA yields are shown from $\mathrm{MCHa}$ and $\mathrm{MCHe}$ ozonolysis around $50 \mathrm{mbar}$ in $\mathrm{He}$, $\mathrm{N}_{2}$ and $\mathrm{SF}_{6}$. The estimated uncertainty is indicated by error bars $(c a . \pm 25 \%)$. The significantly increased SOA yields in terms of number and mass for $\mathrm{SF}_{6}$ and the less pronounced decrease for $\mathrm{He}$ strongly suggests that the suppression is
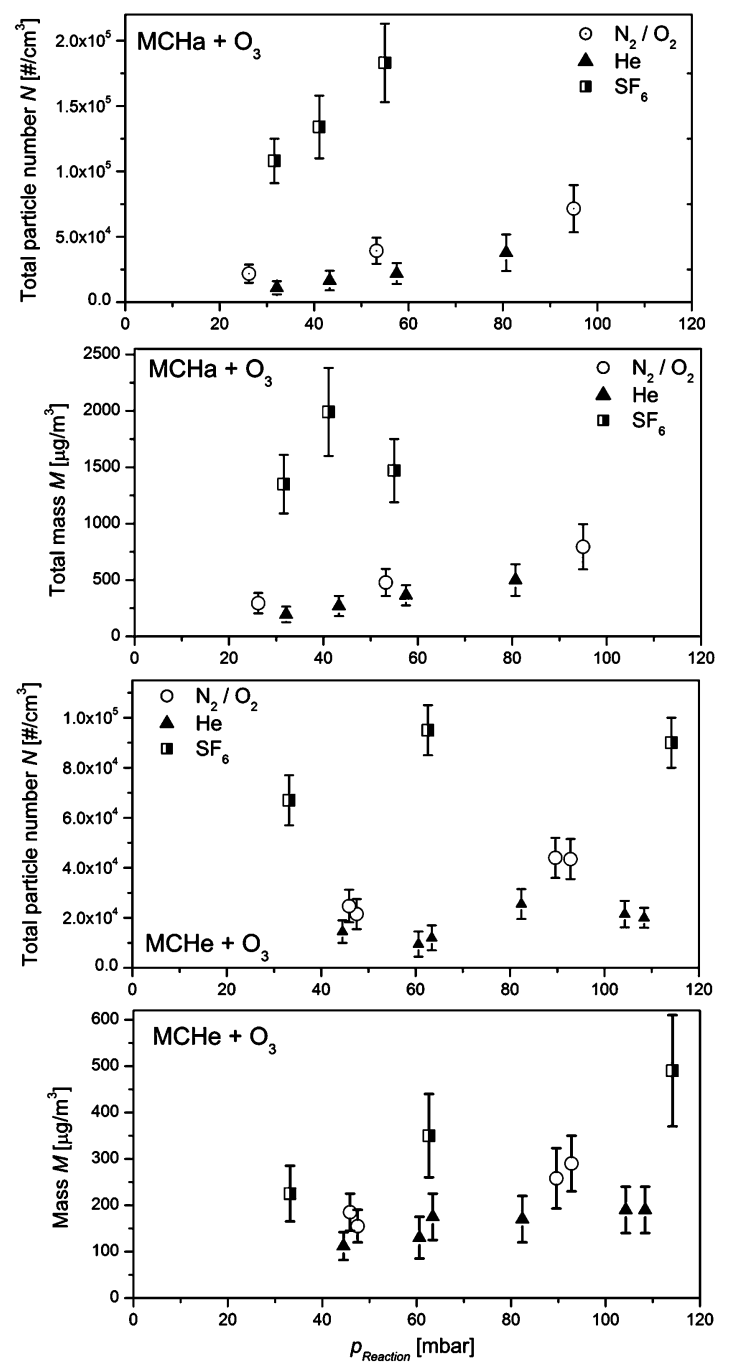

Fig. 6 Aerosol yields in total number and mass are shown as a function of the bath gas (circles: synthetic air; triangles: He; squares: $\mathrm{SF}_{6}$ ) and reaction pressure for the reactions of $0.1 \mathrm{~Pa}(1 \mathrm{ppm}$ at $1 \mathrm{bar})$ ozone with $3 \mathrm{~Pa}$ (30 ppm at 1 bar) $\mathrm{MCHa}$ (upper panels) and $0.2 \mathrm{~Pa}$ ( 2 ppm at 1 bar) $\mathrm{MCHe}$ (lower panels). kinetically controlled. Further evidence for this interpretation comes from another series of experiments. We varied the initial reaction rate at pressures around 40 mbar for $\mathrm{MCHe}+\mathrm{O}_{3}$ by reacting a constant amount of $\mathrm{O}_{3}(0.1 \mathrm{~Pa})$ and varying the $\mathrm{MCHe}$ excess between 0.2 to $2.5 \mathrm{~Pa}$. These kinds of experiments were previously used to assess the influence of wall loss effects on aerosol yields during the ozonolysis of $\beta$-pinene. ${ }^{9}$ The measurements showed no dependence of aerosol yields on the initial reaction rate indicating the absence of wall loss effects. This shows again that the SOA yield reduction is a kinetic effect. However, on this basis we cannot completely exclude a contribution of wall loss effects for experiments below 20 mbar.

The energy loss mechanisms of activated species are very complex. ${ }^{44}$ Therefore the qualitative aspect of these experiments is the most important one: SOA formation pathways from alkene ozonolysis very likely include at least one critical step, which is controlled by chemical activation and collisional stabilisation. This holds at least for cyclic-alkenes including those species being examined in the present study.

With this knowledge we re-examined the effect found in a previous study with a different experimental set-up. With the former set-up we found a suppression of particle formation when large alkene excess concentrations were used for $\mathrm{MCHe}$ and MCHa ozonolysis at $1 \mathrm{bar}^{21}$ However, the preparation of the mixture started at pressures below $10 \mathrm{mbar}$ and with increasing alkene excess the amount of low pressure ozone consumption was increased. The experimentally observed particle formation, however, followed the rate of ozone consumption in the first reaction step indicating secondary ozone chemistry being involved. Taking the present study into account, the residence time in the low pressure regime during mixing and filling would be also closely linked to the ozone/ alkene consumption rate. Therefore an alternative explanation based on the extent of low pressure chemistry is conceivable. Fig. 7 shows the dependence of SOA yields on the alkene excess concentration for $\mathrm{MCHe}$ and $\mathrm{MCHa}$ being reacted with $1 \mathrm{ppm} \mathrm{O}_{3}$ at 1 bar. We see no systematic trend for the particle number concentration and the total particle mass as a function of alkene excess concentration. This implies that the suppression of SOA formation being reported in ref. 21 is most probably a result of low pressure alkene oxidation being described in the present study. We re-evaluated the mixing conditions and found an estimated average reaction pressure of well below 25 mbar at high alkene excess concentrations, explaining the observed suppression of particle formation.

The minor influence of alkene excess concentrations on final SOA yields ensures that the choice of the alkene excess concentrations with respect to the low pressure reaction period is a parameter of minor influence. This was also tested and confirmed for $\alpha$ - and $\beta$-pinene.

At higher alkene excess concentrations the $\mathrm{OH}$ radicals being formed in the ozonolysis will be almost exclusively consumed by the alkene. The effect of the $\mathrm{OH}$ induced oxidation chemistry can be partly reduced by using $\mathrm{OH}$ scavengers such as cyclohexane. However, cyclohexane will form cyclohexylperoxy radicals after $\mathrm{H}$ atom abstraction by $\mathrm{OH}$ changing significantly the $\mathrm{RO}_{2}$ pool in the reaction mixture. We tested the effect of $\mathrm{OH}$ scavenging on the pressure dependent SOA 


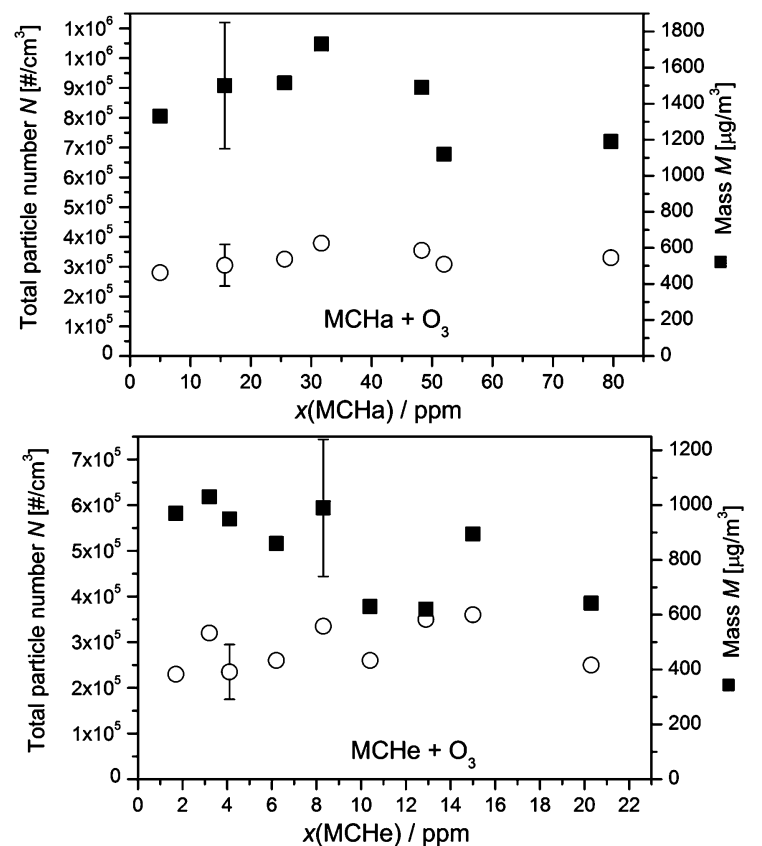

Fig. 7 Aerosol yields in number and mass are shown as a function of the initial alkene concentration for the reactions of $0.1 \mathrm{~Pa}(1 \mathrm{ppm}$ at 1 bar) ozone with $\mathrm{MCHa}$ (upper panel) and $\mathrm{MCHe}$ (lower panel). Experiments were performed around 800 mbar and $298 \pm 1 \mathrm{~K}$.

yield for all alkenes. Absolute aerosol yields were reduced in some of these experiments, the extent of aerosol yield reduction between high and low pressure conditions, however, was similar to the experiments in the absence of cyclohexane. This indicates that the $\mathrm{OH}$ initiated co-chemistry does neither enhance nor suppress the pressure effect.

Comparing the results of ref. 21 and the present study we clearly see that even at high alkene conversion particle formation can be suppressed by addressing critical kinetic parameters. The elucidation of the mechanistic reason in the present study underlines the necessity to control the involved chemical time scales and residence times. Interestingly, a similar development is seen in two recent papers on sulfuric acid based nucleation. The interpretation for the appearance of sulfuric acid induced particle formation at very low concentrations was altered from missing intermediate sulfur chemistry ${ }^{45}$ by experimental progress in controlling cut-off sizes of condensation particle counters, particle growth rates between $c a .1-3 \mathrm{~nm}$ and residence times in flow reactors. ${ }^{46}$ The work of Sipilä et al. ${ }^{46}$ further suggests that $\mathrm{H}_{2} \mathrm{SO}_{4}$ based nucleation can explain atmospheric nucleation events and that organic compounds are mainly involved in particle growth with high uncertainty in the cluster size, where this process becomes relevant. Hence the knowledge of chemical time scales of formation pathways of low volatility products during alkene ozonolysis is mandatory for addressing this issue more rigorously. The pronounced pressure effect on SOA yields reported here is expected to allow insight into the time scales of the intermediate chemistry being involved in SOA formation. Here an improved understanding is needed not only with respect to atmospheric processes but also for a better controlling of laboratory experiments mimicking atmospheric conditions. Based on pressure dependent changes in the final products we could achieve this in a combined experimental and theoretical approach for the much simpler but still complex reaction system of chemically activated cyclic alkoxy radicals. ${ }^{47,48}$ In the next section we will discuss pressure dependent changes in the final gas phase product composition for the alkene $+\mathrm{O}_{3}$ reactions under study.

\section{Product analysis}

The effect of reaction pressure on the final product distribution is studied using IR spectroscopy. The procedure for determining final product concentrations is similar to previous studies. ${ }^{48,49}$ A higher amount of ozone (0.9-1.0 $\mathrm{Pa}, 9-10 \mathrm{ppm}$ at $1 \mathrm{bar})$ compared to the SOA formation experiments was reacted at different pressures and the product spectra were analysed. First the spectra are corrected for not consumed reactants (alkene, ozone) by subtracting pure substance spectra. Then pure substance spectra are subtracted for products being identified by their characteristic absorption bands such that no residuum remains. The error in the concentration determination depends on the absolute product yield and the IR intensity and shape of the product band. It is below $10 \%$, if the product band is clearly distinguishable in the IR spectrum. This is reflected in the errors for the $\mathrm{CO}$ yields given in Table 2 (see e.g. the discussion in ref. 48). When comparing high $(\sim 1000$ mbar $)$ and low pressure $(\sim 50$ mbar $)$ product spectra a general finding is that they are similar in the $\mathrm{C}-\mathrm{H}-$ and $\mathrm{C}=\mathrm{O}$ - stretching regions for all alkenes (see Fig. 8 for $\mathrm{MCHe}$ ). This indicates that the distribution of main products is only slightly changed between products with similar functional groups and carbon back-bone structures. However, some important changes have been found and are discussed below. The increase of the $\mathrm{CO}$ yield at low pressures is a common feature for all alkenes. This increase has been quantified by determining $\mathrm{CO}$ yields relative to the ozone consumption. Here the interference of pressure broadening and the limited IR resolution of $1 \mathrm{~cm}^{-1}$ was taken into account by determining pressure dependent, set-up specific $\mathrm{CO}$ absorption coefficients. ${ }^{50}$ The results are depicted for $\mathrm{MCHa}+\mathrm{O}_{3}$ in Fig. 9 and summarized for all alkenes in Table 2. The CO formation during alkene ozonolysis is known and several channels have been discussed: (1) The isomerisation/decomposition of

Table 2 Alkene $+\mathrm{O}_{3}$ reaction: $\mathrm{CO}$ yields relative to ozone consumption for various pressures ( $T=298 \pm 1 \mathrm{~K}$ for all experiments)

\begin{tabular}{lcl}
\hline Alkene & Pressure $/$ mbar & CO yield \\
\hline $\mathrm{MCHa}^{a, b}$ & 1000 & $0.11 \pm 0.02$ \\
$\mathrm{MCHe}$ & 50 & $0.28 \pm 0.03$ \\
& 1000 & $0.19 \pm 0.02$ \\
& 150 & $0.35 \pm 0.04$ \\
$\alpha$-pinene & 44 & $0.43 \pm 0.04$ \\
& 993 & $0.16 \pm 0.02$ \\
$\beta$-pinene & 80 & $0.23 \pm 0.03$ \\
& 47 & $0.23 \pm 0.03$ \\
& 1000 & $0.05 \pm 0.01$ \\
& 500 & $0.05 \pm 0.01$ \\
& 200 & $0.07 \pm 0.01$ \\
& 80 & $0.09 \pm 0.02$ \\
& 45 & $0.11 \pm 0.02$
\end{tabular}

${ }^{a}$ Additional data for other pressures is given in Fig. 9. ${ }^{b}$ Some experiments were performed in the presence of cyclohexane. 

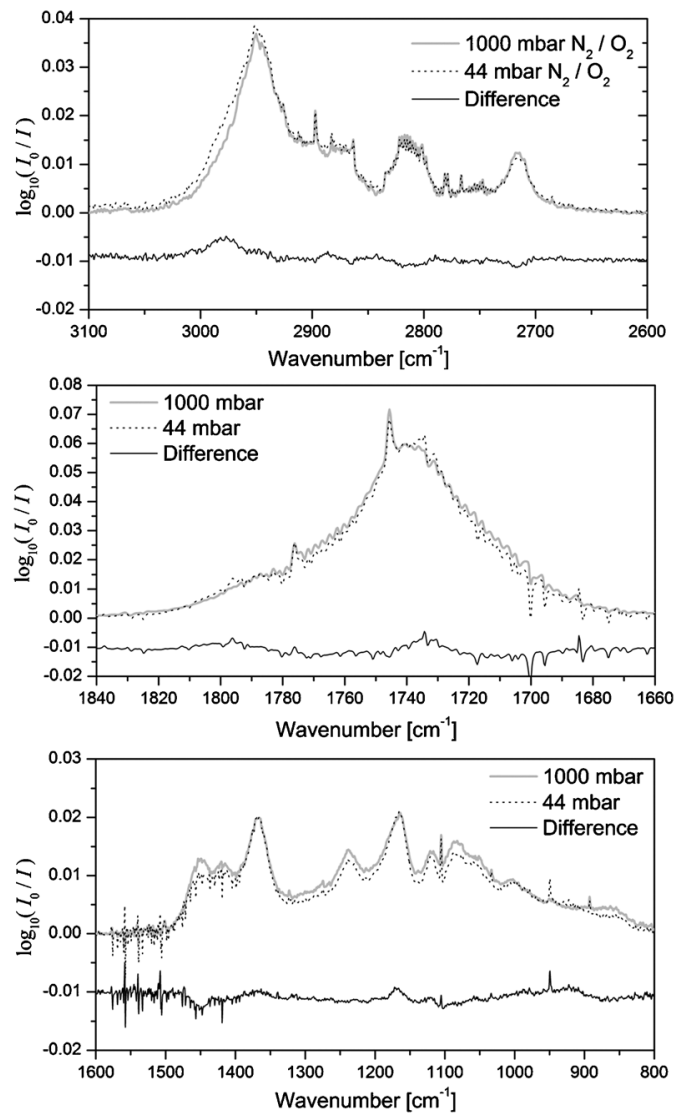

Fig. 8 Pressure dependent product formation from the reaction of $0.9 \mathrm{~Pa}(9 \mathrm{ppm}$ at 1 bar) ozone with $3 \mathrm{~Pa}(30 \mathrm{ppm}$ at $1 \mathrm{bar}) \mathrm{MCHe}$. IR spectra (grey line $1000 \mathrm{mbar}$, broken black line $44 \mathrm{mbar}$, black line difference) of the $\mathrm{C}-\mathrm{H}$ stretching (upper panel), $\mathrm{C}=\mathrm{O}$ stretching (middle panel) and the fingerprint region.

unsubstituted or mono-substituted anti-CIs (ref. 12, see the two upper panels in Fig. 10), (2) consecutive chemistry in the hydroperoxide channel (ref. 12, see two lower panels in Fig. 10), and (3) decomposition of secondary ozonides (ref. 51).

To our knowledge there is no explicit discussion in the literature on the pressure dependence of $\mathrm{CO}$ formation during alkene ozonolysis. The first and the third pathway are mechanistically linked to the lifetime of CIs. The hydroperoxide channel route also involves chemically activated species and may also contribute to enhanced $\mathrm{CO}$ formation at lower pressures. But first we discuss the results for atmospheric pressure.

At 1 bar the absolute $\mathrm{CO}$ yields for all alkenes do agree reasonably well with the assumption that $\mathrm{CI}$ decomposition is the dominating $\mathrm{CO}$ formation route. On the basis of the analogy of 2-methyl-propene and 2-methyl-2-butene being studied by Rickard et al., ${ }^{52}$ we can assume that $c a .30 \%$ of the CIs are not methyl substituted for endocyclic alkenes. When half of these exist in the anti-conformation the absolute $\mathrm{CO}$ yields of $19 \%$ and $16 \%$ for $\mathrm{MCHe}$ and $\alpha$-pinene are only slightly above the estimated fraction of $c a .15 \%$. An alternative estimation by the overall $\mathrm{CO}$ yield of $54 \%$ for mono-substituted CIs in ref. 53 would lead to a similar result. However, for endocyclic alkenes a slight preference for the syn-conformer ( $60 \%$ for cyclohexene) may prevail ${ }^{20}$ thus potentially reducing
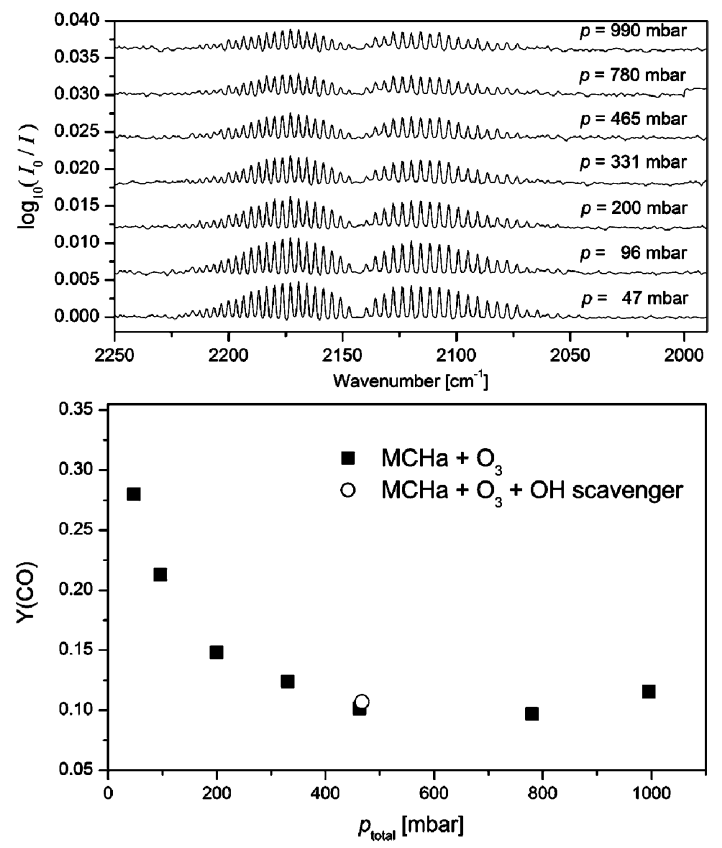

Fig. 9 Pressure dependent formation of $\mathrm{CO}$ from the reaction of $0.9 \mathrm{~Pa}(9 \mathrm{ppm}$ at 1 bar) ozone with $3 \mathrm{~Pa}$ (30 ppm at 1 bar) МCHa. Upper panel: IR spectra of the $\mathrm{C}=\mathrm{O}$ stretching mode. Lower panel: $\mathrm{CO}$ yields relative to ozone consumption as a function of pressure. $T=298 \pm 1 \mathrm{~K}$ for all experiments.

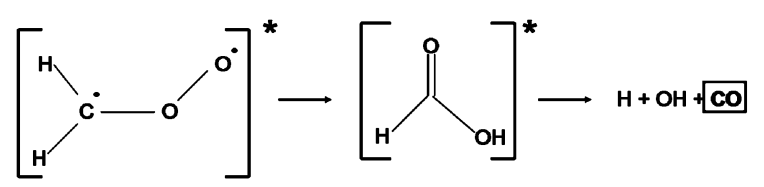

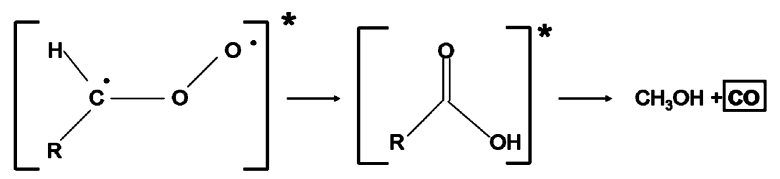

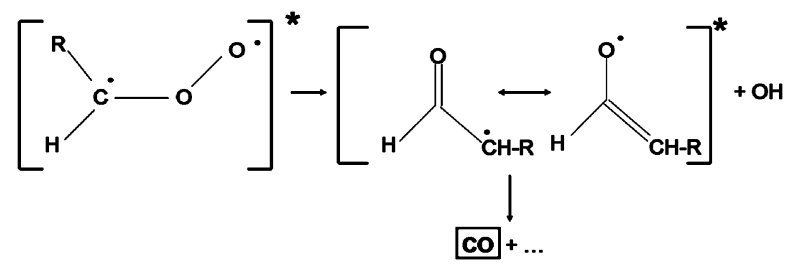

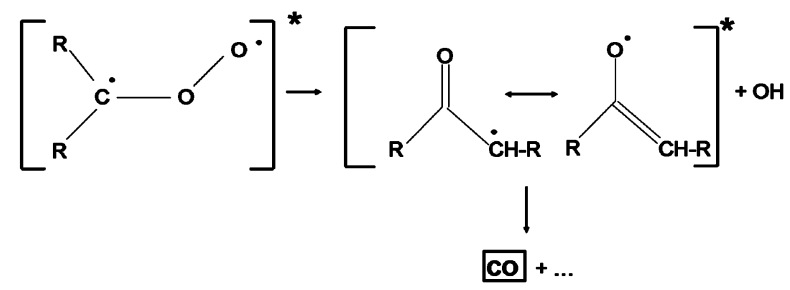

Fig. 10 Possible $\mathrm{CO}$ formation pathways in the alkene ozonolysis mechanism.

the $\mathrm{CO}$ formation via anti-CI decomposition. For the exocyclic alkenes less $\mathrm{CO}$ is formed and $\mathrm{CO}$ formation via $\mathrm{CI}$ decomposition is mechanistically restricted to the unsubstituted $\mathrm{C} 1-\mathrm{CI}$ with a $\mathrm{CO}$ yield of $38 \%$. The literature gives a $16 \%$ fraction of the $\mathrm{C} 1-\mathrm{CI}$ for $\beta$-pinene based on the yield of the corresponding 
carbonyl compound nopinone. For MCHa we found a yield of $c a .30-40 \%$ for cyclo-hexanone giving an estimate for the C1-CI fraction. Hence 0.114-0.152 and 0.061 are the expected $\mathrm{CO}$ yields for $\mathrm{MCHa}$ and $\beta$-pinene via $\mathrm{CI}$ decomposition, which are in reasonable agreement with our experimental findings of 0.11 and 0.05 , respectively. Taking into account the discussion on the $\mathrm{HO}_{2}$ chemistry we note here that a small degree of $\mathrm{O}_{3}$ consumption by $\mathrm{HO}_{2}$ might cause a small systematic error.

Comparing the $\mathrm{CO}$ yields at low and high pressures we see a $\mathrm{CO}$ yield increase by about a factor of 2 (except for $\alpha$-pinene) at low pressures. In the case of $\alpha$-pinene the increase is less pronounced with around $50 \%$. The significant increase of the low pressure $\mathrm{CO}$ yields, above the maximum yields being explained by $\mathrm{CI}$ related decomposition channels, suggests that there is a further source of $\mathrm{CO}$ formation. We note that the implied reduction of stabilised CIs cannot explain an increase of the $\mathrm{CO}$ yield by a factor of 2 at lower pressures. The reduction of stabilised CI concentrations at lower pressures ${ }^{13,17}$ implies higher excess energies of intermediates, formed by CI isomerisation reactions like the species being formed in the hydroperoxide channel. For $\mathrm{MCHa}+\mathrm{O}_{3}$ we see in Fig. 9 that the increase of the $\mathrm{CO}$ yield by reducing the pressure becomes significant between 50-200 mbar. The addition of cyclohexane as an $\mathrm{OH}$ scavenger had no impact on $\mathrm{CO}$ yields (this was also tested with similar results for the other alkenes). Interestingly, this is the pressure range where the reduction of particle formation, especially in terms of mass, becomes more pronounced (see Fig. 5). This suggests that in the case of $\mathrm{MCHa}+\mathrm{O}_{3}$ the concentration of a critical intermediate on the pathway to nucleation inducing species is effectively reduced at lower pressures by its decomposition leading to $\mathrm{CO}$ formation. A possible mechanism is illustrated in Fig. 12(a) for $\mathrm{MCHe}+\mathrm{O}_{3}$. However, a more reliable assignment clearly needs additional evidence from theoretical studies and is beyond the scope of the present study.

For $\alpha$-pinene the increase of $\mathrm{CO}$ formation at lower pressures was less pronounced. Here we observed the formation of ketene $\left(\mathrm{H}_{2} \mathrm{C}=\mathrm{C}=\mathrm{O}\right)$ below $100 \mathrm{mbar}$ being identified by the characteristic peak at $2152 \mathrm{~cm}^{-1} .{ }^{54}$ The upper panel of Fig. 11 illustrates that the relative ketene yield significantly increases when the pressure is reduced from 80 to 20 mbar. Ketene is most likely produced by $\mathrm{C}-\mathrm{C}$ bond fission from the intermediate being formed in the hydroperoxide channel after $\mathrm{OH}$ elimination (see Fig. 12(c)). Seemingly, the loss of this functional site is critical with respect to SOA formation, because its further oxidation is no longer possible. The oxidation of the remaining radical site initiated by $\mathrm{O}_{2}$ addition cannot compensate this effect, at least at lower pressures. For $\alpha$-pinene the decomposition pathway for the keto $\mathrm{CI}$ is similar to $\mathrm{MCHe}$ (see Fig. 12(a)) and can contribute to $\mathrm{CO}$ formation but not to ketene formation. A more detailed study of decomposition pathways in the hydroperoxide channel including theory seems promising because it offers access to the unimolecular chemistry of CI decomposition products. In a recent experimental and theoretical study ${ }^{48}$ on the decomposition pathways of chemically activated cycloalkoxy $\left(\mathrm{C}_{6} \mathrm{H}_{11} \mathrm{O}\right.$ and $\mathrm{C}_{8} \mathrm{H}_{15} \mathrm{O}$ ) radicals, we characterised the decomposition of the second stage products in the unimolecular chemistry and

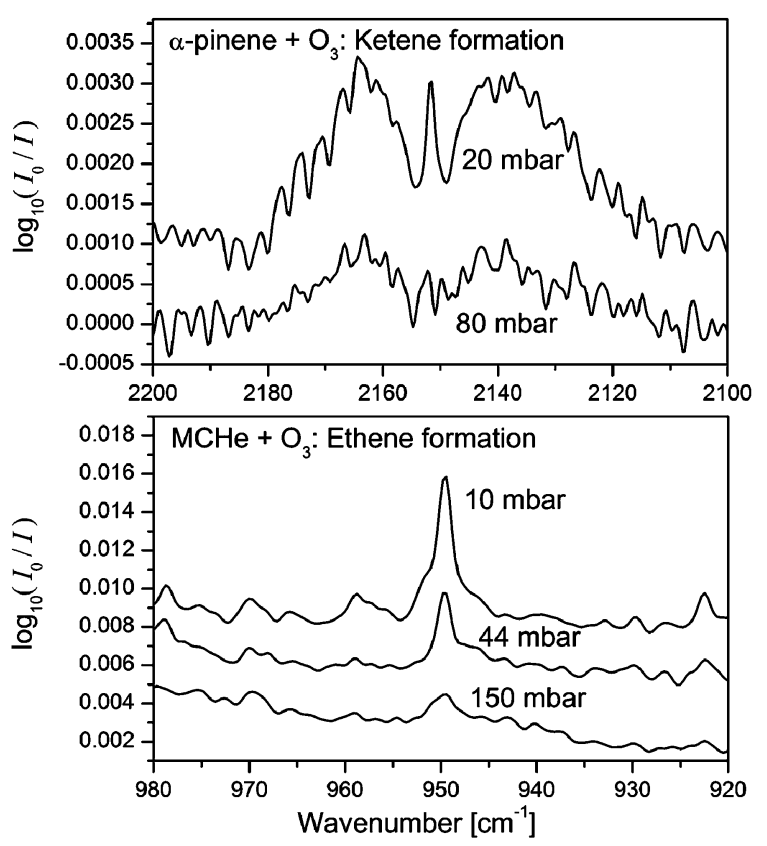

Fig. 11 Pressure dependent formation of ketene (upper panel) from the reaction of $0.9 \mathrm{~Pa}$ ( $9 \mathrm{ppm}$ at 1 bar) ozone with $3 \mathrm{~Pa}$ (30 ppm at $1 \mathrm{bar}$ ) $\alpha$-pinene and ethene (lower panel) from the reaction of $0.9 \mathrm{~Pa}$ ozone with $3 \mathrm{~Pa} \mathrm{MCHe}$.

their pressure dependency. Here ethene formation is a reliable marker for the decomposition of ring opening products of the type * $\mathrm{R}-\left(\mathrm{CH}_{2}\right)_{n}-\mathrm{CHO}$, where $\mathrm{C}_{2} \mathrm{H}_{4}+\mathrm{R}-\left(\mathrm{CH}_{2}\right)_{n-2}-\mathrm{CHO}$ is the dominating decomposition channel (See Fig. 12(d)). The high excitation energy of the cyclic alkoxy radicals when formed from $\mathrm{R}+\mathrm{O}\left(\sim 375 \mathrm{~kJ} \mathrm{~mol}^{-1}\right)$ implies a rapid decomposition of the ring opening product in most cases and allowed the identification of the critical conditions, when it starts to be collisionally stabilised. In the present study the lower excess energy of primary ozonides (200-250 $\mathrm{kJ} \mathrm{mol}^{-1}$ ) allows the identification of intermediate species being less stabilised at lower pressures. The panels (b), (c) and (d) of Fig. 12 illustrate that similar intermediates are involved with an aldehyde group and a radical site at the ends of the carbon chain. Interestingly, for the $\mathrm{MCHe}+\mathrm{O}_{3}$ reaction we found the formation of ethene at lower reaction pressures together with the formation of ketene. In Fig. 12(b) a conceivable mechanism is depicted for the concerted formation of ethene and ketene from the aldehydic CI. The route illustrated in Fig. 12(a) starting from the keto CI gives a possible explanation for the increased $\mathrm{CO}$ formation and may be an additional source of ethene. We note that ethene formation from $\alpha$-pinene $+\mathrm{O}_{3}$ is hindered by the internal ring (see Fig. 12(c)) and is not observed for $\alpha$-pinene. The ethene yield increases from $5 \%$ at $150 \mathrm{mbar}$ to $18 \%$ at $10 \mathrm{mbar}$, which represents a surprisingly high fraction. The reaction alkene $+\mathrm{O}_{3}$ as a source for ketene and ethene formation was confirmed in experiments in the presence of the $\mathrm{OH}$ scavenger cyclohexane (35 Pa), which showed identical ethene and ketene yields. Clearly, the mechanisms depicted in Fig. 12(a)-(c) need additional confirmation. The significant pressure dependence starting between 100-200 mbar suggests that only one further bond scission is involved (being energetically not too expensive) 


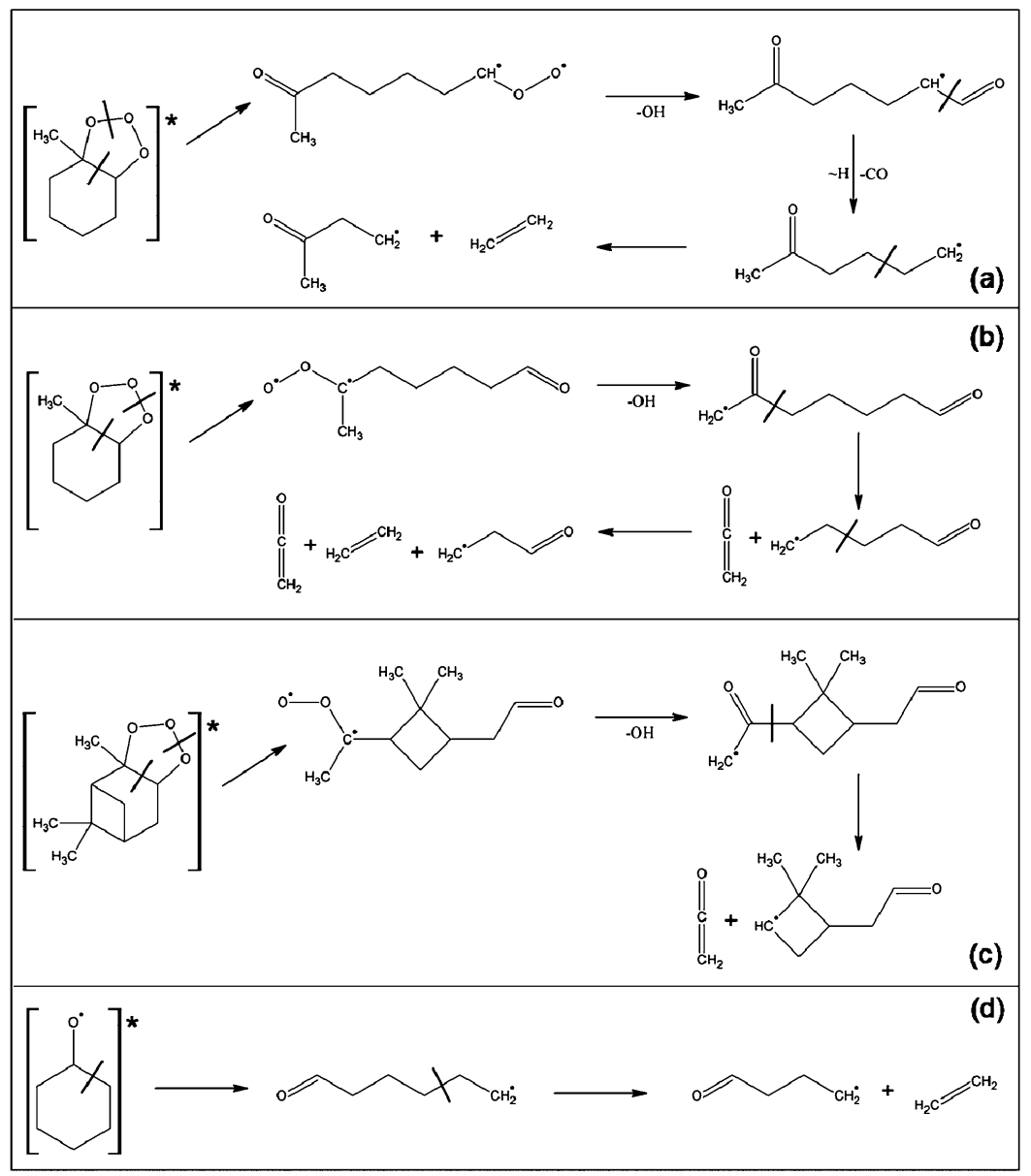

Fig. 12 (a-c) Possible formation pathways of ketene, ethene and $\mathrm{CO}$ at lower pressures from $\alpha$-pinene $+\mathrm{O}_{3}$ and $\mathrm{MCHe}+\mathrm{O}_{3}$. (a) $\mathrm{MCHe}$ : ethene and $\mathrm{CO}$ formation from the keto CI. (b) MCHe: ketene and ethene formation from the aldehydic CI. (c) $\alpha$-pinene: ketene formation from the aldehydic CI. (d) Ethene formation from the decomposition of chemically activated cyclo-hexoxy radicals (ref. 42).

after the CI stage and that the source has a rather short chemical lifetime. This points indeed to the hydroperoxide channel. The later steps in the gas phase ozonolysis mechanism become more complicated due to the interference of secondary chemistry linked to $\mathrm{O}_{2}$ and $\mathrm{RO}_{2} / \mathrm{HO}_{2}$ radical reactions and the decomposition channels of substituted alkoxy radicals as demonstrated recently for $\alpha$-pinene and $\beta$-pinene. ${ }^{55-57}$ The results of the present study indicate a significant pressure dependence of that part of this chemistry, which is connected to SOA and SOA component formation.

A further item in the product analysis is the pronounced difference in the fingerprint region when comparing the low and high pressure IR product spectra from $\beta$-pinene ozonolysis: The double peak around $1100 \mathrm{~cm}^{-1}$ in the 1 bar spectrum vanishes when the reaction pressure is lowered (see Fig. 13). In a previous study this band has been assigned to the secondary ozonide (SOZ) ${ }^{58}$ The result shows that the formation of a species of low volatility is suppressed at low reaction pressures. This holds especially when the SOZ is considered, which is formed from the ring $\mathrm{CI}$ with nopinone. Analysing the 1 bar and 50 mbar product spectra around $1100 \mathrm{~cm}^{-1}$ from $\mathrm{MCHa}$ ozonolysis reveals the formation of a species absorbing in this region being suppressed at lower pressures (not shown). We can tentatively assign this band to the corresponding $\mathrm{SOZ}$ but the results are less conclusive than for $\beta$-pinene with the respect to the much lower signal-to-noise ratio. For MCHe and $\alpha$-pinene no specific SOZ bands were found. This is in line with ref. 20, which reported that the lifetimes of CIs from endocyclic alkene ozonolysis are much shorter compared to exocyclic alkenes. The vanishing $\mathrm{SOZ}$ bands for the exocylic alkenes at lower pressures can be explained by the reduced yield of stabilised CIs at low pressures which in consequence suppresses the formation of the $\mathrm{SOZ}$ in bimolecular reactions with carbonyl compounds. An alternative explanation is the pressure dependence of $\mathrm{SOZ}$ decomposition being discussed above in the context of $\mathrm{CO}$ formation. But this is questionable with respect to the scarceness of stabilised CIs at lower pressures.

In summary we found that the main product formation is only slightly effected by pressure reduction for the alkene $+\mathrm{O}_{3}$ reactions under study in agreement with a recent theoretical study on $\beta$-pinene ozonolysis. ${ }^{13}$ However, products with pressure dependent yields have been found for each alkene, which are in the case of $\mathrm{CO}$, ketene and ethene most probably related to the chemistry beyond the CI stage in the hydroperoxide channel. These observations give some information about the mechanism being responsible for the pressure dependent SOA yields. A straightforward explanation is as follows: The intermediate 


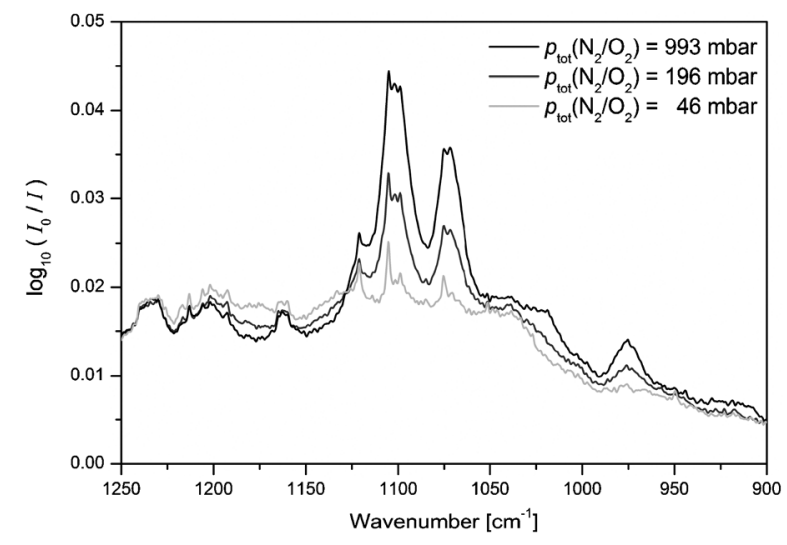

Fig. 13 Product spectra in the fingerprint region from the reaction of $1 \mathrm{~Pa}$ (10 ppm) ozone with $\beta$-pinene at $993 \mathrm{mbar}, 196 \mathrm{mbar}$ and $46 \mathrm{mbar}$.

alkyl radicals shown in Fig. 12 are the critical species on the pathway to nucleation inducing species. Lower pressures imply that $\mathrm{O}_{2}$ addition to these species and isomerisation to more stable intermediates and the final products of lowest volatility are less competitive than the suggested decomposition channels. In consequence the concentrations of nucleation inducing species drop as the yields of the decomposition channels increase. At pressures below 10 mbar the decomposition of intermediates in the hydroperoxide channel dominates for all alkenes under study and the SOA yields are below $10 \%$ of the 1 bar value.

However, there are other mechanisms, being not mutually exclusive, which emphasise the formation of chemically bonded dimers in the gas phase. Such a mechanism was suggested by Heaton et al. ${ }^{23}$ and SOZ formation is an example being discussed above and in the literature. ${ }^{6}$ In this scenario it is conceivable that intermediates being long lived at 1 bar (e.g. CIs) become short lived at low pressures and cannot form chemically bonded "dimers" in the gas phase. This would mean that the forward reaction of dimer formation is suppressed. It is also conceivable that chemically activated dimers are formed from intermediate or stable species. These products of low volatility are not stabilised at low pressure and decompose, which means that the backward reaction is enhanced. The present study allows to specify that the monomers are not two stable species. Then SOA formation would start immediately when the reaction mixture is filled to $1 \mathrm{bar}$ for SOA analysis. Conclusions on this important issue seem possible when a detailed theoretical modelling of the life times/chemical activation and the channel branching of these intermediates is provided.

The present study further shows that SOA formation is closely linked to tropospheric pressure. In general, the pressure effect on new particle formation could be a significant aspect for our understanding of extraterrestrial atmospheres, which exhibit aerosol chemistry with Titan being a prominent example. ${ }^{59}$

\section{Conclusions}

A new experimental set-up allowing the fast mixing of reactants is used to study the effect of pressure during the gas phase ozonolysis of the alkenes MCHe, MCHa, $\alpha$-pinene and $\beta$-pinene. The main result is that the SOA formation can be substantially suppressed at lower reaction pressures for all alkenes under study. A series of test experiments confirmed that a reduced collisional stabilisation of intermediate species is most likely the reason for this effect. The comparison of pressure dependent final product and aerosol yields showed that $\mathrm{CO}$ formation in the case of $\mathrm{MCHa} / \beta$-pinene, ketene formation in the case of $\alpha$-pinene and ethene/ketene formation in the case of $\mathrm{MCHe}$ start to increase significantly at pressures where the reduction of SOA formation intensifies. Comparison with the $\alpha$-pinene ozonolysis mechanism indicates that ketene is produced by the decomposition of the intermediate resulting from $\mathrm{OH}$ elimination in the hydroperoxide channel. In general, identifying critical intermediates for SOA formation at stages after the CI isomerisation/decomposition and studying their dynamics by pressure variation is a promising approach to infer the gas phase mechanisms that lead to SOA formation.

\section{Acknowledgements}

The continuous support of this work by Prof. Martin Suhm and Prof. Karlheinz Hoyermann is gratefully acknowledged. We thank the "Deutsche Forschungsgemeinschaft" (GRK 782) and the "Fonds der Chemischen Industrie" for funding.

\section{Notes and references}

1 J. H. Seinfeld and J. F. Pankow, Ann. Rev. Phys. Chem., 2003, 54, 121.

2 Q. Zhang, et al., Geophys. Res. Lett., 2007, 34, L13801.

3 F. Went, Nature, 1960, 187, 641.

4 A. H. Goldstein and I. E. Galbally, Environ. Sci. Technol., 2007, 41, 1514.

5 M. Claeys, B. Graham, G. Vas, W. Wang, R. Vermeylen, V. Pashynska, J. Cafmeyer, P. Guyon, M. O. Andreae, P. Artaxo and W. Maenhaut, Science, 2004, 303, 1173.

6 B. Bonn and G. K. Moortgat, Atmos. Chem. Phys., 2002, 2, 183; B. Bonn, G. Schuster and G. K. Moortgat, J. Phys. Chem. A, 2002, 106, 2869.

7 J. B. Burkholder, T. Baynard, A. R. Ravishankara and E. R. Lovejoy, J. Geophys. Res., 2007, 112, D10216.

8 S. Lee and R. M. Kamens, Atmos. Environ., 2005, 39, 6822.

9 R. Pathak, N. M. Donahue and S. N. Pandis, Environ. Sci. Technol., 2008, 42, 5081.

10 S. Gao, M. Keywood, N. L. Ng, J. Surratt, V. Varutbangkul, R. Bahreini, R. C. Flagan and J. H. Seinfeld, J. Phys. Chem. A, 2004, 108, 10147.

11 J. E. Shilling, Q. Chen, S. M. King, T. Rosenoern, J. H. Kroll, D. R. Worsnop, P. F. DeCarlo, A. C. Aiken, D. Sueper, J. L. Jimenez and S. T. Martin, Atmos. Chem. Phys, 2009, 9, 771.

12 D. Johnson and G. Marston, Chem. Soc. Rev., 2008, 37, 699.

13 T. L. Nguyen, J. Peeters and L. Vereecken, Phys. Chem. Chem. Phys., 2009, 11, 5643.

14 J. D. Fenske, A. S. Hasson, S. E. Paulson, K. T. Kuwata, A. Ho and K. N. Houk, J. Phys. Chem. A, 2000, 104, 7821.

15 J. H. Kroll, J. S. Clarke, N. M. Donahue, J. G. Anderson and K. L. Demerjian, J. Phys. Chem. A, 2001, 105, 1554; J. H. Kroll, S. R. Sahay, J. G. Anderson, K. L. Demerjian and N. M. Donahue, J. Phys. Chem. A, 2001, 105, 4446.

16 S. Hatakeyama, H. Kobayashi, Z.-Y. Lin, H. Takagi and H. Akimoto, J. Phys. Chem., 1986, 90, 4131.

17 M. Olzmann, E. Kraka, D. Cremer, R. Gutbrod and S. Andersson, J. Phys. Chem. A, 1997, 101, 9421.

18 R. Criegee, Angew. Chem., Int. Ed. Engl., 1975, 14, 745.

19 R. Gutbrod, R. N. Schindler, E. Kraka and D. Cremer, Chem. Phys. Lett., 1996, 252, 221.

20 B. Chuong, J. Zhang and N. M. Donahue, J. Am. Chem. Soc., 2004, 126, 12363.

21 J. L. Wolf, M. A. Suhm and T. Zeuch, Angew. Chem., Int. Ed., $2009,48,2231$. 
22 M. L. Walser, Y. Desyaterik, J. Laskin, A. Laskin and S. A. Nizkorodov, Phys. Chem. Chem. Phys., 2008, 10, 1009.

23 K. J. Heaton, M. A. Dreyfus, S. Wang and M. V. Johnston, Environ. Sci. Technol., 2007, 41, 6129.

24 J. L. Wolf, Dissertation, Universität Göttingen, Logos Verlag, Berlin, 2010.

25 R. D. Cusick and R. Atkinson, Int. J. Chem. Kinet., 2005, 37, 183.

26 M. Witter, T. Berndt, O. Böge, F. Stratmann and J. Heintzenberg, Int. J. Chem. Kinet., 2002, 34, 394.

27 P. Neeb and G. K. Moortgat, J. Phys. Chem. A, 1999, 103, 9003.

28 E. Grosjean and D. Grosjean, Int. J. Chem. Kinet., 1997, 29, 855.

29 S. Koch, R. Winterhalter, E. Uherek, A. Kolloff, P. Neeb and G. K. Moortgat, Atmos. Environ., 2000, 34, 4031.

30 D. Johnson, A. R. Rickard, C. D. McGill and G. Marston, Phys. Chem. Chem. Phys., 2000, 2, 323.

31 J. Treacy, M. Curley, J. Wenger and H. Sidebottom, J. Chem. Soc., Faraday Trans., 1997, 93, 2877.

32 R. Atkinson, D. Hasegawa and S. M. Aschmann, Int. J. Chem. Kinet., 1990, 22, 871.

33 V. G. Khamaganov and R. A. Hites, Int. J. Chem. Kinet., 1990, 22, 871.

34 R. Tillmann, H. Saathoff, T. Brauers, A. Kiendler-Scharr and T. F. Mentel, Phys. Chem. Chem. Phys., 2009, 11, 2323.

35 T. L. Malkin, A. Goddard, D. E. Heard and P. W. Seakins, Atmos. Chem. Phys., 2010, 10, 1414.

36 R. Atkinson, D. L. Baulch, R. A. Cox, R. F. Hampson Jr., J. A. Kerr and J. Troe, J. Phys. Chem. Ref. Data, 1992, 21, 1125

37 R. Wegener, T. Brauers, R. Koppmann, S. Rodriguez Bares, F. Rohrer, R. Tillmann, A. Wahner, A. Hansel and A. Wisthaler, J. Geophys. Res., 2007, 112, D13301.

38 J. H. Kroll and J. H. Seinfeld, Environ. Sci. Technol., 2005, 39, 4159.

39 J. H. Kroll and J. H. Seinfeld, Atmos. Environ., 2008, 42, 3593.

40 M. Hallquist, J. C. Wenger, U. Baltensperger, Y. Rudich, D. Simpson, M. Claeys, J. Dommen, N. M. Donahue, C. George, A. H. Goldstein, J. F. Hamilton, H. Herrmann, T. Hoffmann, Y. Iinuma, M. Jang, M. Jenkin, J. L. Jimenez, A. Kiendler-Scharr, W. Maenhaut, G. McFiggans, T. F. Mentel, A. Monod, A. S. H. Prévôt, J. H. Seinfeld, J. D. Surratt, R. Szmigielski and J. Wildt, Atmos. Chem. Phys., 2009, 9, 5155.

41 T. Zeuch, G. Moréac, S. S. Ahmed and F. Mauss, Combust. Flame, $2008, \mathbf{1 5 5}, 651$.
42 H. Hippler, J. Troe and H. J. Wendelken, J. Chem. Phys., 1983, 78, 6709.

43 E. L. Cussler, Diffusion-Mass Transfer in Fluid Systems, Cambridge University Press, Cambridge, New York, 1997.

44 J. Troe, J. Phys. Chem., 1979, 83, 114.

45 T. Berndt, O. Böge, J. Heintzenberg and M. Kulmala, Science, 2005, 307, 698.

46 M. Sipilä, T. Berndt, T. Petäjä, D. Brus, J. Vanhanen, F. Stratmann, J. Patokoski, R. L. Mauldin, A.-P. Hyvärinen, H. Lihavainen and M. Kulmala, Science, 2010, 327, 1243.

47 K. Hoyermann, J. Nothdurft, M. Olzmann, J. Wehmeyer and T. Zeuch, J. Phys. Chem. A, 2006, 110, 3165.

48 K. Hoyermann, S. Maarfeld, F. Nacke, J. Nothdurft, M. Olzmann, J. Wehmeyer, Ol. Welz and T. Zeuch, Phys. Chem. Chem. Phys., 2010, 12, 8953.

49 W. Hack, K. Hoyermann, M. Olzmann and T. Zeuch, Proc. Combust. Inst., 2002, 29, 1247.

50 W. Hack, M. Hold, K. Hoyermann, J. Wehmeyer and T. Zeuch, Phys. Chem. Chem. Phys., 2005, 7, 1977.

51 P. Neeb, O. Horie and G. K. Moortgat, J. Phys. Chem. A., 1998, 102, 6778 .

52 A. R. Rickard, D. Johnson, C. D. McGill and G. Marston, J. Phys. Chem. A, 1999, 103, 7656.

53 B. Qi, B. Yang, Z. Wang, H. Yang and L. Liu, Sci. China, Ser. B: Chem., 2009, 52, 356.

54 J. L. Duncan, A. M. Ferguson, J. Harper, K. H. Tonge and F. Hegelund, J. Mol. Spectrosc., 1987, 122, 72.

55 Y. Ma, T. Luciani, R. A. Porter, A. T. Russel, D. Johnson and G. Marston, Phys. Chem. Chem. Phys., 2007, 9, 5084.

56 Y. Ma, A. T. Russel and G. Marston, Phys. Chem. Chem. Phys., 2008, 10, 4294.

57 L. Vereecken and J. Peeters, Phys. Chem. Chem. Phys., 2009, 11, 9062.

58 R. Winterhalter, P. Neeb, D. Grossmann, A. Kolloff, O. Horie and G. K. Moortgat, J. Atmos. Chem., 2000, 35, 165.

59 G. Israël, C. Szopa, F. Raulin, M. Cabane, H. B. Niemann, S. K. Atreya, S. J. Bauer, J.-F. Brun, E. Chassefière, P. Coll, E. Condé, D. Coscia, A. Hauchecorne, P. Millian, M.-J. Nguyen, T. Owen, W. Riedler, R. E. Samuelson, J.-M. Siguier, M. Steller, R. Sternberg and C. Vidal-Madjar, Nature, 2005, 438, 796 . 